\title{
Reliability of Soil and Ground Improvement Techniques on Peaty Clay Soil - A Review
}

\author{
Akpila, S. B. ${ }^{1}$, Jaja, G. W. T. ${ }^{2}$ \\ ${ }^{1}$ Department of Civil Engineering, ${ }^{2}$ Faculty of Engineering \\ 1,2Rivers State University, Nkpolu Port Harcourt, Nigeria
}

\begin{abstract}
How to cite this paper: Akpila, S. B. I Jaja, G. W. T. "Reliability of Soil and Ground Improvement Techniques on Peaty Clay Soil - A Review" Published in International Journal of Trend in Scientific Research and Development (ijtsrd), ISSN: 24566470, Volume-3 | Issue-3 , April 2019, pp.682-690, URL: http://www.ijtsrd.co $\mathrm{m} /$ papers/ijtsrd229 09.pdf

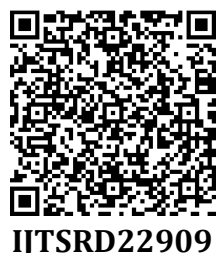

Copyright (C) 2019 by author(s) and International Journal of Trend in Scientific Research and Development Journal. This is an Open Access article distributed under the terms of the Creative Commons

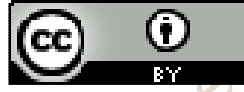
Attribution License (CC BY 4.0) (http://creativecommons.org/licenses/ by $/ 4.0$ )

\section{INTRODUCTION}

The soil in diverse regions have a lot of foundation issues which include high ground table water, deformation of the highly compressive clays, peat, etc. Most areas of these zones are water logged, swampy and characterized by weak soils, thus making it difficult to put a structure on them without addressing the stability of such structures. A land based structure is as strong as its foundation. Thus the soil is a critical element that influences the success of any structure placed on it. Due to the nature of the soils in some regions, there are inherent foundation problems such as deformation, consolidation of highly compressible clays and settlement just to mention a few. Ground improvement is needed for some projects with a view to maximize the durability of the natural soil for a given construction purpose.

Soil improvement increases strength, bearing capacity and resistance to deteriorating forces of nature and man-made environment. It decreases the volume change tendency, settlement, controls permeability and provides long term permeability over decades of service under severe environmental conditions. Soil improvement changes the engineering properties of the soil to allow for field construction to take place on weak soils. The long term performance of structures, be it roads, buildings, slopes, embankments or any other structure depends on the soundness of the underlying soils; unsuitable soils can create significant problems. In the light of this, ground improvement techniques are used to allow for optimal utilization of sites or ground with poor subsurface conditions. In view of these challenges, it is necessary in some cases to improve the soil before structures are placed on them, it is expedient to investigate modern trends in ground improvement techniques like the use of cement, calcium compounds etc. in order to determine their reliability. In order to achieve the above mentioned objectives, the research involved getting results on unconfined compressive strength test and California bearing ratio test on the natural soil samples taken at shallow depths of 1-1.5 m below ground level, and those improved with cement, calcium compounds etc. within selected geographical regions. Reliability index method of analysis is used to obtain the reliability of various ground improvement methods used in this study, with a view to comparing them and determination of how reliable they are in improving the strength of the soils in the study areas [1].

\section{LITERATURE REVIEW}

Description and Geotechnical Characteristics of the soil Soil is a broad term used to describe loose deposits, created from the underlying rocks by physical, synthetic and natural procedures which fluctuate with time, area and ecological conditions and results in an extensive variety of soil 
properties [2]. Soils in some regions are fluviatile in nature comprising of water-logged overwhelming soil, secured by peat. The soil in coastal zones is underlain by a fluctuating grouping of sand and clay, with a high rate of occurrence of clay within $10 \mathrm{~m}$ below the ground surface. Soil in these regions has low load bearing limit, materials with the voids filled with water; in this manner their significant engineering issues includes the abundance of surface and ground water, poor drainages, high compressibility, low bearing capacity and differential settlements. It is emphasized that extensive leaching out of salt by rain water and ground water cause detrimental effect on soil structure [3].

\section{Ground Improvement}

Ground improvement is any process of altering unsuitable in situ or borrowed soil to improve selected engineering characteristics, at a lower cost and with better quality control than can be obtained by replacement, bridging over or by passing the unsuitable material [4]. From the above definition, inference is drawn that ground improvement is the modification of existing site foundation soils to provide better performance under design or operational loading conditions.

Ground improvement is both an art and a science with significant developments observed through ancient history. For example, elephants were used for compaction of earth dams during the early Asian civilization, woven reed mats were embedded in sand between bricks for drainage, straws blended in fills with soils for additional strength during the ancient Roman civilization, the Mesopotamians and Romans separately discovered that it was possible to improve the ability of pathways to carry traffic by mixing weak soils with agents like pulverized limestone or calcium. Meanwhile the idea of inclusions for improving and strengthening of soil dates back to $3000 \mathrm{BC}$ in present day Iraq and China.

Hamidi et al. [5] believes that Loius Menard invented dynamic compaction as early as 1969 , but it was not until May 1970 that he formally patented invention in France. The concept of his technique is improving the mechanical properties of the soil by transmitting high energy impacts to the soil, by dropping a heavy pounder from a significant height. According to Mitchell [6] when feasible, dynamic compaction is probably the most favorable ground improvement technique in granular soils because it is usually the most economical soil improvement solution.

These methods of improving soil without the addition of agents or materials have evolved over years to include techniques like: deep dynamic compaction, Vibrocompaction, Compaction grouting, Pre-loading and Prefabricated vertical drains, fast densification and surface compaction.

The use of geo synthetic products for ground improvement began many years before it had a name. The terms geo textile and geo synthetic were not coined until Dr J. P. Giroud used those terms in a seminar paper and presentation at an engineering conference in Paris in 1977 [7].

Ground improvement methods are used to stabilize or enhance the performance of poor inadmissible subsurface soils and or to improve the performance of embankments, structures, or subsurface systems [8]. Generally, these methods are used when replacements of the unacceptable, in-situ soils are impractical or too expensive.

\section{Functions of Ground Improvement}

An inadequately performing soil needs to be improved upon to enhance one or more of the following primary functions [8];

1. Increase or stabilize bearing capacity or shear strength.

2. Limit and control non-uniform or excessive deformations.

3. Accelerate primary consolidation.

4. Decrease long term total settlement.

5. Provide and increase stability.

6. Provide seepage cut offs or control.

7. Minimize the amount of detrimental voids.

These functions depend on the strategy to be adopted in enhancing the soil to be improved upon. Some of the strategies adopted in practice [9] are:

1. Consolidation

2. Reinforcement

3. Load Reduction

4. Densification

5. Soil Mixing

6. Grouting

7. Load Transfer.

The selection of an ideal ground improvement technique is based on performance, constructability, cost and any other relevant project factors and can either be a permanent measure which is to improve the completed facility or a temporary process to allow the construction of the facility [10].

\section{Classification of Ground Improvement Methods}

According to Purushotama [10], ground improvement methods or techniques might be arranged by the nature of procedure adopted, materials utilized and the craved results. Various methods of ground improvements have been classified [11].

$>$ Mechanical Improvement techniques

$>$ Hydraulic modification

$>$ Physical and chemical modification

$>$ Inclusion and confinement

$>$ A combination of all of the above.

\section{Mechanical Improvement method}

This method improves the unsuitable soil through the application of mechanical force. This method may be achieved in many ways which include:

$>$ Dynamic compaction

$>$ Vibro-compaction

$>$ Compaction grouting

$>$ Blast-densification

\section{Physical and Chemical Modification Method}

Soil improvement in this method is achieved by physical mixture of adhesives with surface layers or columns of soil. The adhesives include natural soils, industrial bye products, waste materials, chemicals or materials that are cementatious, which react with each other and the soil. Physical and chemical methods used for ground improvement include:

1. Grouting:-is a ground improvement method often used for und erground and foundation constructions. The New York department of Transportation (NYDOT) Geotechnical design manual [12] categorizes grouting materials along these lines; 
$>$ Particulate grouting which can be suspension or cementious.

$>$ Colloidal solutions

$>$ Pure solutions

$>$ Miscellaneous materials

2. Electro-osmosis

3. Soil cement

4. Heating

5. Vitrification

\section{Modification by inclusion and confinement}

Improvement of soil properties by this method uses fibers, strips, bar fabrics and meshes to impart tensile strength on a soil mass [11]. Some techniques under this method include:

1. Stone columns

2. Dynamic replacement method

3. Sand Compaction piles

4. Geo textile confined columns

5. Reinforcement method: Geo synthetics a mechanically stabilized earth walls are examples of this method.

There are other conventional and unconventional methods which are also in used in diverse countries where these products are readily available and easily accessible, and economically reasonable to them.

\section{Reliability in Geotechnical Engineering}

Reliability is a probabilistic way of measuring the performance of geotechnical systems, using techniques that are at variance with the traditional factor of safety approach. This technique for measuring performance can be qualitatively referred to as the probability of success or nonfailure is a compliment for the probability of failure and it is necessary in Geotechnical engineering due to the shortcomings of assessing the safety of a geotechnical systems using factor of safety.

Geotechnical engineers deal with materials in which loads and resistances are combined and whose distribution and properties are not well known thereby bringing in uncertainties in design. These uncertainties in geotechnical materials can be tackled by an observational method [13]. This method basically pints to the fact that it is hardly feasible to assume values of loads and properties of materials conservatively for design purposes in geotechnical applications. Though reliability analysis cannot get rid of uncertainties, but it can provide a means of handling them in a consistent manner and giving a sensible quantification. Also, the fact that it removes the need for guess work on how uncertainties affect performance of a geotechnical system, makes it a technique that is worthwhile [1].

As a probabilistic tool, reliability is the probability that a system will perform its intended function for a specific period of time under a given $m$ set of conditions, or the probability that unsatisfactory performance or failure will not occur meaning that the reliability analysis depends essentially on the theory of probability and statistics as an essential technical pillar for its rise and recognition in the field of geotechnical engineering [14]. Basically, reliability based design has an objective of offering satisfactory system performance with the constraint of the economy in geotechnical engineering.

\section{Methods of Probabilistic Reliability Analysis (Reliability Models)}

Probabilistic reliability analysis methods have common characteristics. Their common characteristics are:-

$>$ They are normally defined by random variables and their underlying distributions.

$>$ They are based on limit states (analytical equations)

$>$ They are based on capacity or factor of safety relationships.

These methods which are tools used in determining the reliability index and by extension the probability of failure of geotechnical systems are:

$>$ First order second moment (FOSM) otherwise known as Taylors series.

$>$ Point estimate method

$>$ Hasofer - Lind method (FORM)

$>$ Monte carlo simulation method

The methods have their advantages and short comings, Hasofer - Lind method which is also called first order reliability method proposes a new definition for reliability index using geometric interpretation while the Monte-Carlo method uses simulation based on randomized input.

\section{Steps in Reliability Analysis}

These steps include the following:

$>$ Establishment of the model for analysis

$>$ Estimation of the statistical description of parameters

$>$ Determination of statistical moments of performance of the function

$>$ Determination of the reliability index $\beta$

Q Computation of the probability of failure Pf, a complement of the reliability index.

In establishing an analytical method, a measure of performance of the system must be established. This can be done through the computation of margin of safety, factor of safety or any other measure that is appropriate. Statistical parameters which are normally described by their mean, variances and covariance must include the properties of the geotechnical materials as well as their relationships.

\section{Reliability Equation: FOSM Method of Analysis}

First Order Second Moment method of analysis uses the first term of Taylor's series expansion of the performing function in estimating the expected value (mean) and variance of the performing function. Once the expected value and the variance are obtained for the load and resistance, obtaining the reliability of the geotechnical system or the probability of failure as the case may be will no longer be a cumbersome affair.

\section{Assumptions in Reliability Equation}

The basic assumptions in adopting this method of analysis are;

$>$ The load Q is normalized

$>$ The resistance $\mathrm{R}$ is normalized

$>$ The safety margin $\mathrm{M}$ which is the performance function of the geotechnical system is normalized by virtue of the above assumptions.

Relationship between Reliability, Load and Resistance Most problems in geotechnical engineering are described in terms of load $\mathrm{Q}$ and resistance $\mathrm{R}$. The load $\mathrm{Q}$ being the load applied to the geotechnical system and the resistance $\mathrm{R}$ 
being the ability of the system to resist the load. According to Gregory and John [13], loading and resistance must be taken on their broadest sense. Reliability analysis deals with the relation between the loads a system must carry and its ability to carry the loads, this is normally expressed in the form of a reliability index which is related to the probability of failure.

Factor of safety (FS) assess the safety of soil structure system using these two point estimates: load $Q$ and resistance $\mathrm{R}$; thus $\mathrm{FS}=\mathrm{R} / \mathrm{Q}$

From the above equation, $F S \geq 1.0$, the structure is considered safe and unsafe when FS $<1.0$. Reliability is a better approach that takes care of the short comings of the above conventional measure of safety by treating both the load $Q$, and the resistance $\mathrm{R}$ as random variables represented through their probability density functions. Due to the uncertainty of these variables statistically, they must have a mean or an expected value, variances and covariance.

\section{MATERIALS AND METHODS}

The materials used in this study

$>$ hemicals

$>$ eotextiles

Soil Sample - Soil samples of marine clay, which are peaty in nature were obtained from diverse locations. With the use of hand augers, the soil samples were taken at depths of $1 \mathrm{~m}$ for California Bearing Ratio (CBR) tests while samples for the unconfined compressive strength tests (UCS) were taken at depths of $1 \mathrm{~m}$ to $1.5 \mathrm{~m}$. The soil samples where properly sealed to prevent the loss or gain of moisture.

Chemicals - The cement used in this study is Ordinary Portland Cement (OPC) grade 42.5. Other chemicals that are multivalent and monovalent cationic species like Calcium
Oxide (CaO), Sodium Silicate $\left(\mathrm{Na}_{2} \mathrm{SiO}_{3}\right)$, Aluminum Hydroxide $(\mathrm{AlOH})_{3}$, Calcium Chloride $\left(\mathrm{CaCl}_{2}\right)$, and Calcium Hydroxide $\left(\mathrm{Ca}(\mathrm{OH})_{2}\right)$ where used in the study to improve the engineering properties of the various soil samples in order to determine their reliability.

$>$ Sodium Silicate $(\mathrm{Na} 2 \mathrm{SiO3})$ is a white powder that belongs to the family of sodium metasillicate. It is readily soluble in water, thus an alkaline solution. It is a non-polluting, environmentally safe and non-hazardous to human health.

$>$ Calcium Oxide $(\mathrm{CaO})$ otherwise known as quick lime is a chemical reagent which can effectively control the swelling of soils by modifying its properties especially the plastic characteristics. Its ability to form alkaline solutions and suspensions in water is very key to its modification of soils in a beneficial way to engineers. Its improvement of soil is majorly due to pozzolanic reactions which allow it to improve the long term performance of soils significantly [15].

$>$ Calcium Hydroxide $\mathrm{Ca}(\mathrm{OH}) 2$ is also referred to as slake lime, a name it got through the process of mixing calcium oxide with water (slaking) at temperatures below $350^{\circ} \mathrm{C}$. It is an inorganic compound that is colorless and crystal white in color.

Aluminum Hydroxide $(\mathrm{Al}(\mathrm{OH}) 3)$ is found in nature as hydragillite (Gibbsite), it is quite environmentally friendly and does not appear to be extremely sensitive to moisture content variations. Freshly precipitated type of this chemical forms a gel that crystallizes with time and can be hydrated to form an amorphous (solid) Aluminum hydroxide powder.

Calcium Chloride, $\mathrm{CaCl} 2$, is the combination of calcium and chloride, which behaves like an ionic halide, which is solid at room temperature. Due to its solubility, it can be a source of calcium ions in a solution.

The physical and chemical properties of the chemicals in this study are shown in the Table 1.

\begin{tabular}{|c|c|c|c|c|c|}
\hline CHEMICALS & $\begin{array}{c}\text { MOLAR MASS } \\
\mathrm{g} / \mathrm{mol}\end{array}$ & $\begin{array}{l}\text { MELTING } \\
\text { POINT }{ }^{\circ} \mathrm{C} \\
\end{array}$ & $\begin{array}{c}\text { DENSITY } \\
\mathrm{g} / \mathrm{cm}^{3} \\
\end{array}$ & SOLUBILITY & ACIDITY \\
\hline CALCIUM OXIDE & 56.0774 & 2,572 & 3.34 & In water and glycerol & 12.8 \\
\hline SODIUM SILICATE & 122.06 & 1,088 & 2.40 & In water & 11.3 \\
\hline ALUMINIUM HYDROXIDE & 78 & 300 & 2.42 & In acids and alkalis & $>7$ \\
\hline CALCIUM CHLORIDE & 110.98 & 772 & 2.15 & In water, acetic acid & $8-9$ \\
\hline CALCIUM HYDROXIDE & 74.093 & 580 & 2.21 & In water, acids and glycerol & 12.4 \\
\hline
\end{tabular}

Geo textiles - Woven and non-woven types of geo textiles were considered in the study for CBR test in order to determine their reliability on the improvement of properties of the various soil samples.

\section{METHODS}

\section{Proctor and CBR compaction tests with Chemicals}

Cement and other chemicals used for the study i.e. Calcium chloride, Sodium silicate, Calcium hydroxide, Aluminum hydroxide, Calcium oxide where added to prepared samples of the soil passing BS sieve $425 \mu \mathrm{m}$ from various locations, in different percentages of soil: $2 \%, 4 \%, 6 \%, 8 \%$ and $10 \%$. The improved soil samples were cured for 7, 14 and 28 days with the use of polythene bags after maximum dry density and Optimum moisture content have been determined from the standard proctor compaction tests, while CBR tests were carried out in accordance with BS 1377 [16].

\section{Proctor and CBR tests with Geo textile materials}

Two types of geo textile materials were applied in this study; woven and unwoven. After the proctor compaction and curing, the geo textile materials were placed in between the surcharge rings of the CBR machine and the top of the soil samples in the mould before the test was carried out for both the soaked and un soaked conditions in accordance with BS $1377[16]$.

\section{Unconfined Compressive Strength (UCS) Test}

The unconfined compressive strength test was carried out on the various undisturbed soil samples in accordance with BS 1377. Cylindrical soil samples of the natural soil and those treated with various percentages of cement: $2,4,6,8$ and $10 \%$ respectively, of the weight of soil were prepared at the natural moisture content and dry unit weight. After compaction, samples were cured for 7, 14 and 28 days 
before the UCS test was carried out with a cell pressure of 50 $\mathrm{kN} / \mathrm{m}^{2}$ and $100 \mathrm{kN} / \mathrm{m}^{2}$.

Mathematically the Reliability is derived using the following

First Moment (Expected Mean):

$\mu=E(\mathrm{X})=\sum_{i=1}^{n} x P(X=x)$

This can also be defined as;-

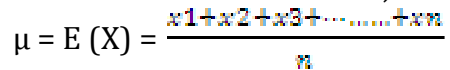

Second Moment (Variance):

$\sigma^{2}=E\left(\mathrm{x}^{2}\right)-[E(\mathrm{x})]^{2}=E\left(\mathrm{x}^{2}\right)-\mu^{2}$

Standard Deviation:

$\sigma=\sqrt{ } \sigma^{2}=\int_{-\infty}^{\infty} x f x(x-m)^{2} d x$

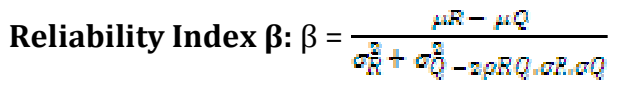

Practical application of the mathematical formulation is such that once the reliability index $(\beta)$ is calculated using appropriate formulas, if the value is negative the reading on the standard normal distribution table is the probability of failure $\left(\mathrm{P}_{f}\right)$ of the system, from which the Reliability $R_{e}$ of the system ca be obtained thus $R_{e}=1-P_{f}$.

If the value of the reliability index $\beta$ is positive, then the reading on the standard normal distribution table becomes the Reliability Re of the system. From these mathematical expressions it can be deduced that as the Reliability index $\beta$ increases, the probability of failure decreases thereby making the Reliability index $\beta$ similar in behavior to the factor of safety.

\section{RESULTS AND DISCUSSION}

Graphs showing Reliability Values for unconfined compressive strength (UCS) test of Peaty clay mixed with various percentages of chemicals and curing periods in the various locations of study are shown in Figure 1 - Figure 12.

Reliability values obtained in this study for soil samples mixed with various percentages of Calcium Oxide show an appreciable result with the peak at $6 \%$. As observed from Figure 1, the difference in reliability values between 7 to 14 days curing periods shows some disparity in comparison with that of 14 to 28 days curing period. Calcium oxide shows maximum reliability of all the chemicals used in the research with a sharp decrease from $8 \%$ to $10 \%$ especially for the 7 days curing in the UCS test.

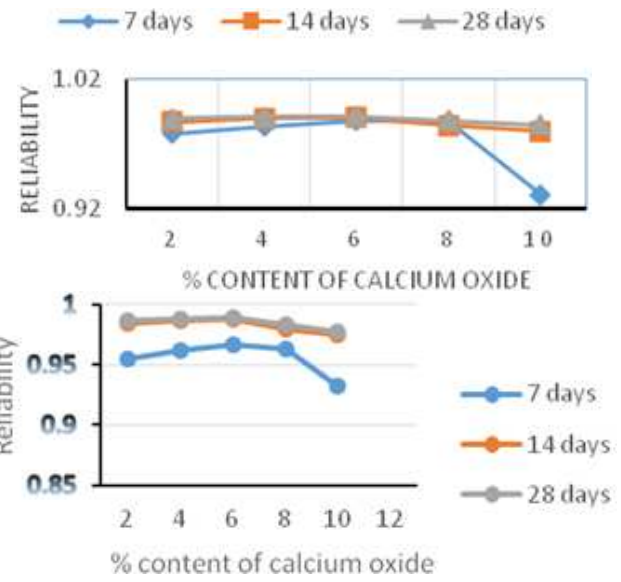

Figure 1: Reliability versus \% Calcium Oxide and curing for UCS test at Location 1 and 2
Calcium Hydroxide is a by-product of calcium oxide and figure 2 shows that the reliability behavior follows the same trend as that of calcium oxide but with lower values. From the values above, it can be observed that the reliability value for the optimal percentage ( $6 \%$ ) are close for all the curing days, while the reliability from $6 \%$ on the addition of chemicals up to $10 \%$, are similar to that of calcium oxide.

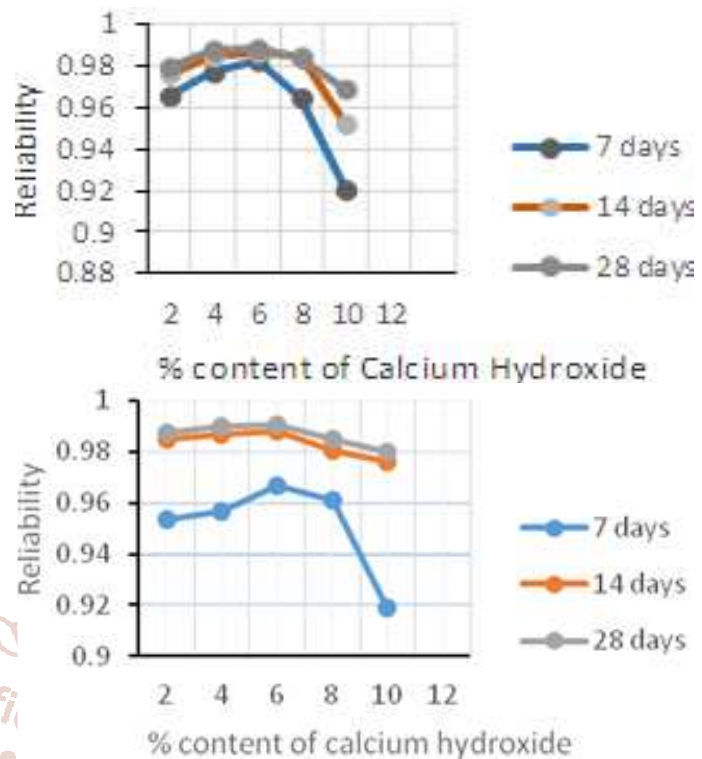

Figure 2: Reliability versus \% Calcium Hydroxide and curing for UCS test at Location 1 and 2.

Figure 3 shows the reliability of soil samples mixed with Calcium Chloride. Similarly, the reliability peaked is at $6 \%$ for all curing days, with a sharp reliability values for the UCS test equal at $2 \%$ and $4 \%$, while the reliability starts reducing from $6 \%$ to $10 \%$. At the peak value, there is a large disparity between 14 and 28 days of curing but the difference between the values of the 7 and 14 days is negligible.
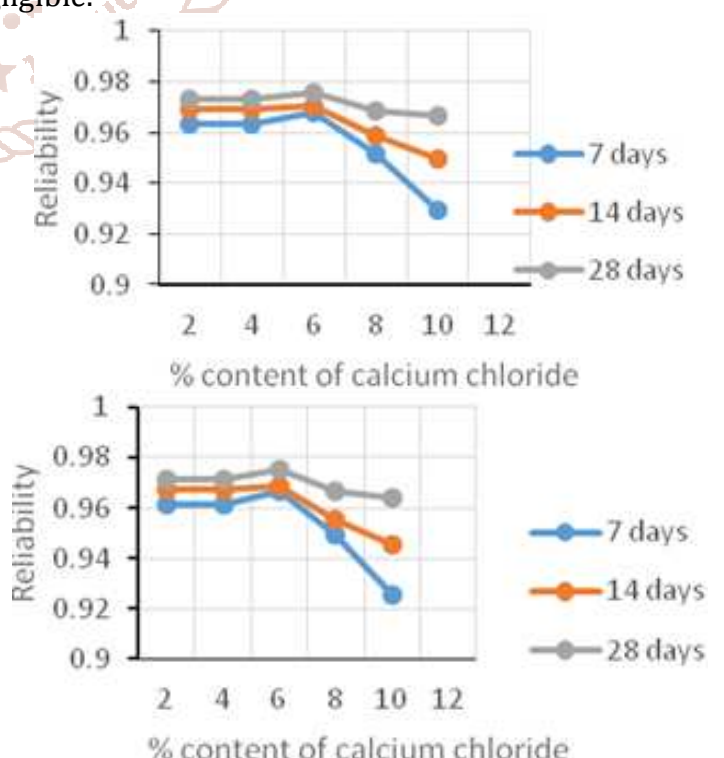

Figure 3: Reliability versus \% Calcium Chloride and curing for UCS test at Location 1 and 2

Figure 4 shows that the reliability increases with an increase in the cement and with the period of curing up to $10 \%$ of cement in the soil and a 28 days curing period. Cement is the only material that has exhibited this behavior (increase till the summit), of all the materials used in this study. 


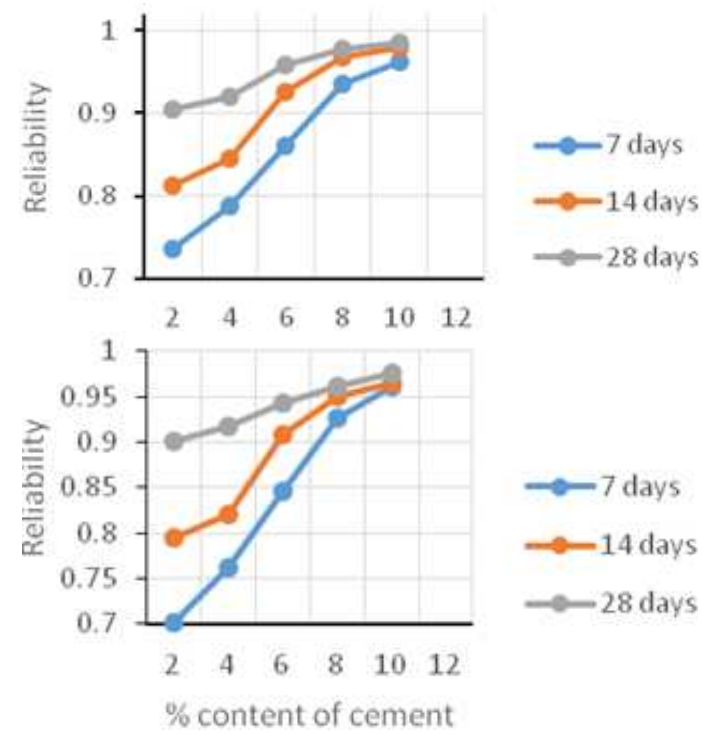

Figure 4: Reliability versus \% Cement and curing for UCS test at Location 1 and 2

Aluminum hydroxide is a component of gibbsite, which forms part of the three main phases of the rock bauxite. From Figure 5 the reliability peaked at $4 \%$ for 14 and 28 days curing, while 7 days of curing peaked at $6 \%$ before a gradual slide in value with the 7 days curing period experiencing the highest slide in reliability.
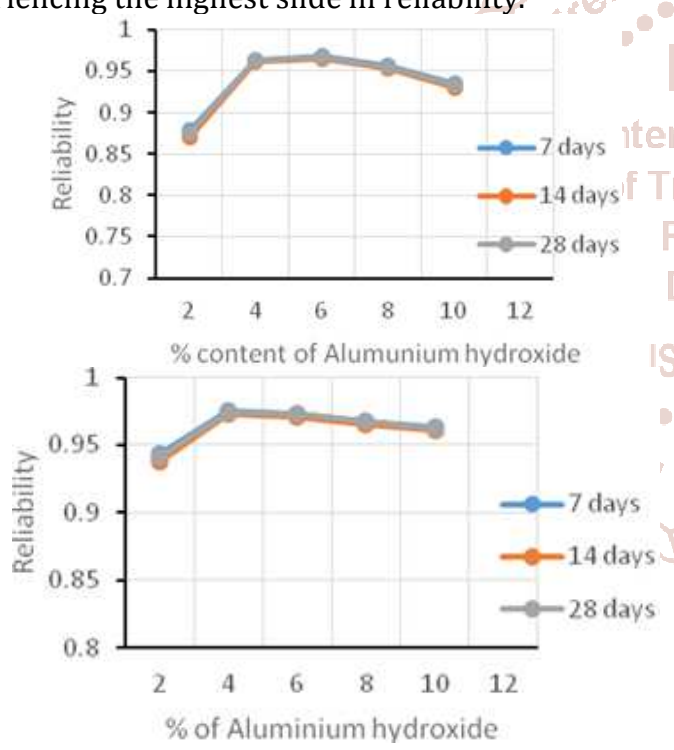

Figure 5: Reliability versus \% Aluminum Hydroxide and curing for UCS test at Location 1 and 2.

Figure 6 shows that the soil improved with sodium silicate, at an optimal level of $8 \%$ in UCS tests and for all periods of curing. It was the only chemical with the reliability level above $6 \%$ apart from cement that optimized at $10 \%$. Significant reduction in reliability for all curing periods can be observed when more than $8 \%$ of the chemical is added to the soil sample for improvement.

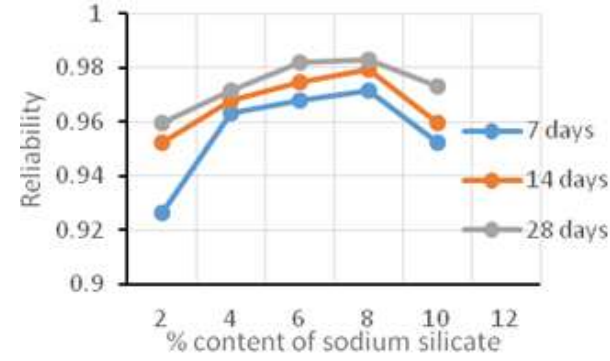

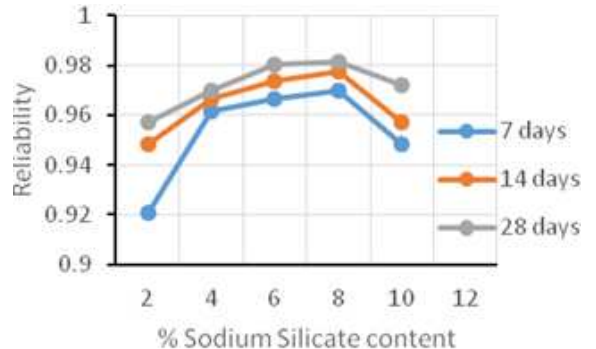

Figure 6: Reliability versus \% Sodium Silicate and curing for UCS test at Location 1 and 2.

The reliability values obtained through the reliability index and the plot of the variation of the reliability with the percentages of Calcium Oxide and curing days in the CBR test are shown in figure 7.
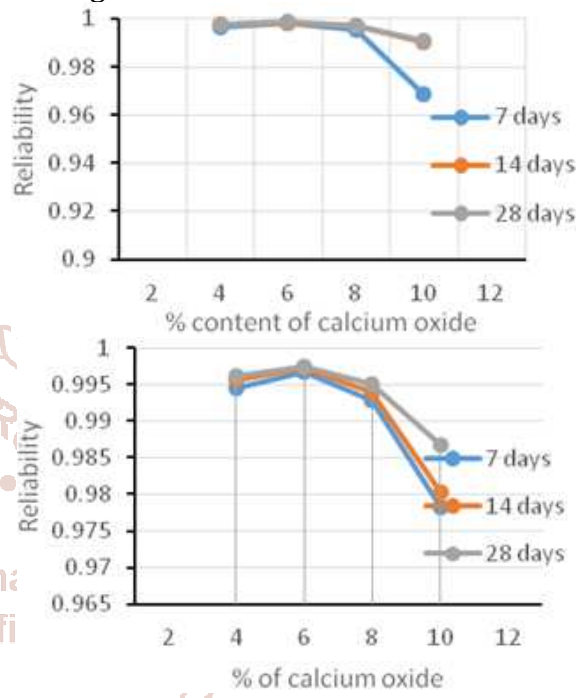

Figure 7: Reliability versus \% Calcium oxide and curing for CBR test at Location 1 and 2.

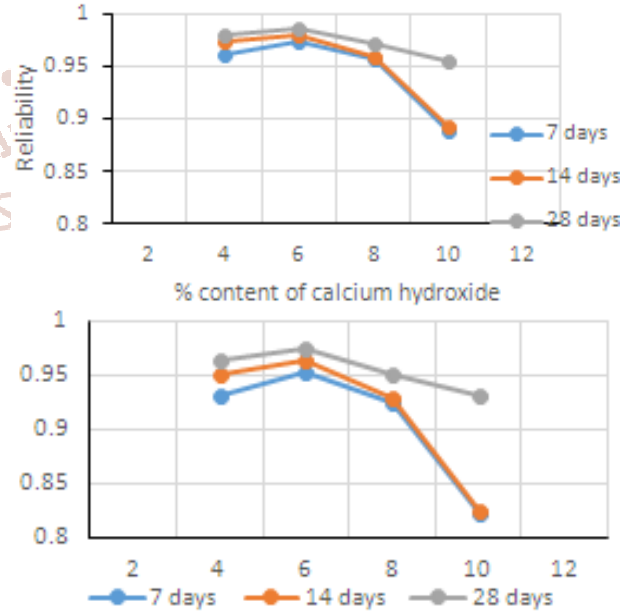

Figure 8: Reliability versus \% Calcium hydroxide and curing for CBR test at Location 1and 2.

In figure 8, the reliability variation with the percentage of Calcium hydroxide and curing for CBR test is depicted. Calcium Hydroxide had the third best reliability values after calcium oxide and cement. And in figure 9, there is a negligible difference in reliability values especially between 7 and 14 days of curing, from 8 to $10 \%$ addition of Calcium Chloride. It shows the reliability values for CBR tests for the various percentages of the chemical added to the soil sample and the reliability variation with the percentage of Calcium chloride in the improvement process and the number of curing days. 

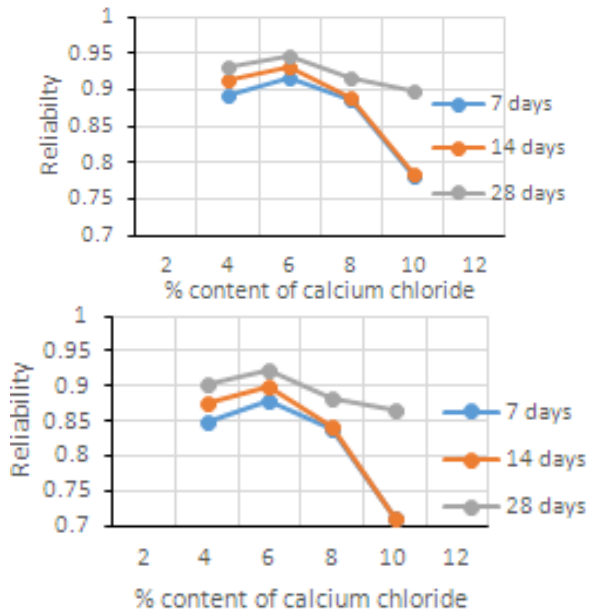

Figure 9: Reliability versus \% content of Calcium Chloride and curing for CBR test at Location 1 and 2.

The plot on figure 10 shows how the reliability varies with percentage addition of cement to the soil, with their curing periods. The reliability increases with an increase in the cement and they have their peak curing periods at 28 days with $10 \%$ cement.

In figure 11 , the variation of reliability with percentage addition of cement to the soil and curing period is presented. Reliability peaked at $4 \%$ for both 14 and 28 days curing, while that of 7 days peaked at $6 \%$. Aluminum hydroxide is the only chemical that peaked at $4 \%$

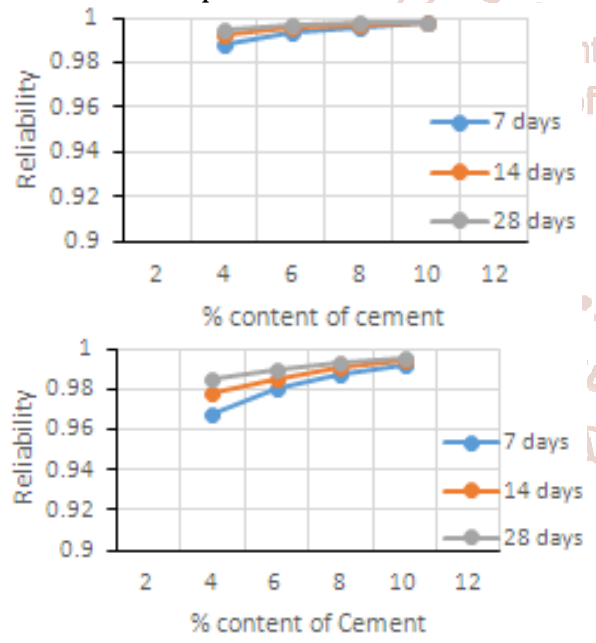

Figure 10: Reliability versus content of Cement and curing for CBR test at Location 1 and 2.
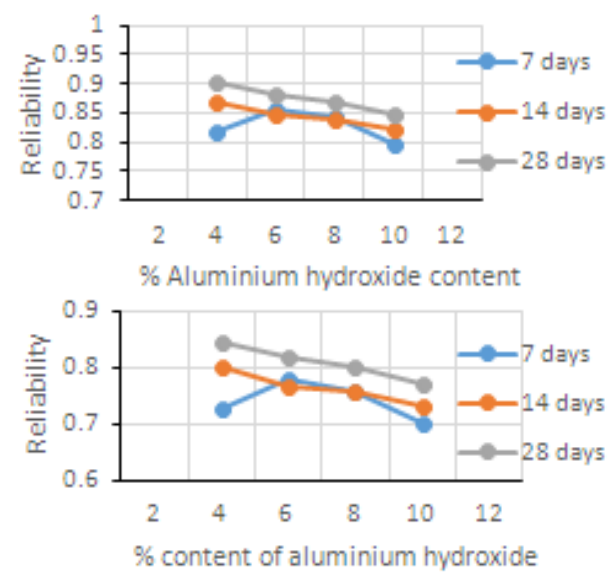

Figure 11: Reliability versus Aluminum Hydroxide and curing for CBR test at Location 1 and 2.
Figure 12 shows the variation of the reliability values with percentage addition of Sodium silicate and curing days. Soil improved when sodium silicate attained optimal reliability at $8 \%$ in CBR tests and this is the only chemical with reliability level above $6 \%$ addition of chemical. Also, a significant reduction in reliability for all curing periods can be observed, when more than $8 \%$ of the chemical is added to the soil sample.
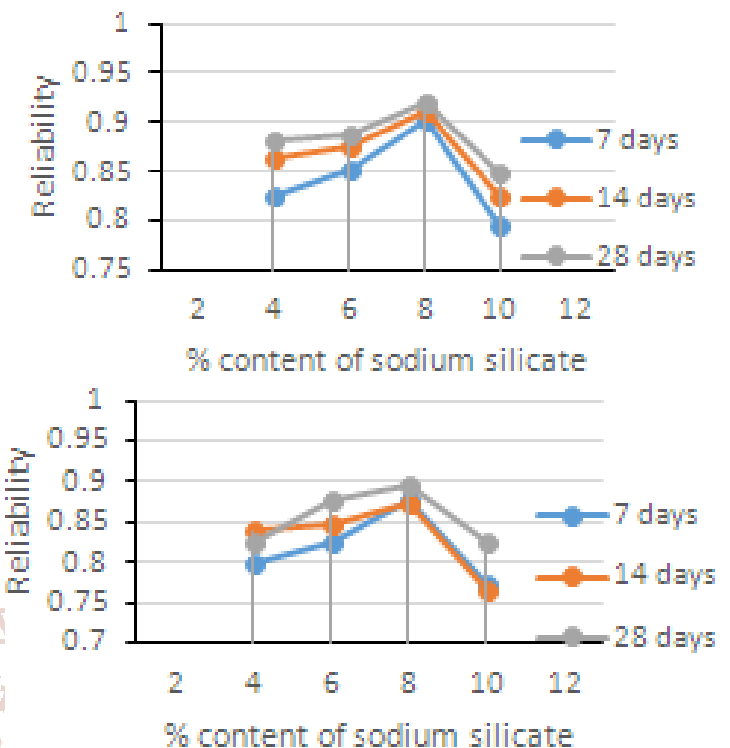

Figure 12: Reliability versus \% Sodium Silicate and curing for CBR test at Location 1 and 2.

In the plot of reliability values against the tensile strength of geo textile materials (Figures 13 and 14), it is observed that reliability is directly proportional to the tensile strength of the geo textile materials. It is noteworthy, that the highest reliability value as seen in the un soaked condition of the woven geo textile is so low that it can only lead to an unacceptable performance when applied on peaty clay. From Table 2, even though all the values are very low it is observed that the woven geo textiles have better reliability value for both soaked and un soaked conditions of the CBR than the non-woven.

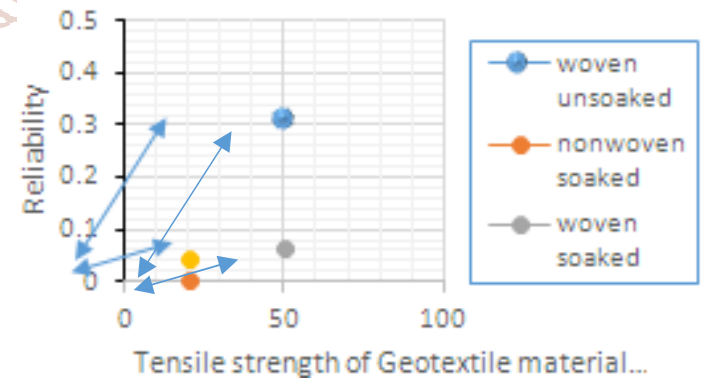

Figure 13: Variation of Reliability with tensile strength of geo textile materials at Location 1

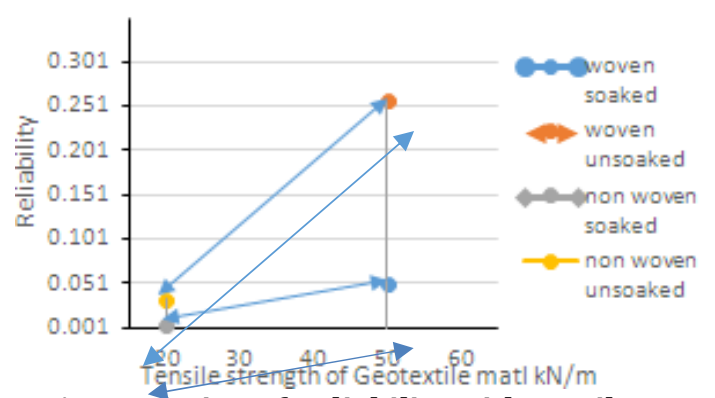

Figure 14: Variation of Reliability with tensile strength of geo textile materials at Location2 
International Journal of Trend in Scientific Research and Development (IJTSRD) @ www.ijtsrd.com eISSN: 2456-6470

Table 2: Reliability Values Summary for CBR test on Peaty Clay improved with Geotextile materials in the locations of study

\begin{tabular}{|c|c|c|}
\hline Location & Materials & Reliability Values \\
\hline \multirow{4}{*}{1} & Peaty Clay Soaked & 0.0010 \\
\cline { 2 - 3 } & Peaty Clay Un soaked & 0.0044 \\
\cline { 2 - 3 } & Peaty Clay + Woven Geo textile Soaked & 0.0668 \\
\cline { 2 - 3 } & Peaty Clay + Woven Geo textile Un soaked & 0.3085 \\
\cline { 2 - 3 } & Peaty Clay + Non-Woven Geo textile Soaked & 0.0036 \\
\cline { 2 - 3 } & Peaty Clay + Non-Woven Geo textile Un soaked & 0.0427 \\
\hline \multirow{5}{*}{2} & Peaty Clay Soaked & 0.0008 \\
\cline { 2 - 3 } & Peaty Clay Un soaked & 0.0034 \\
\cline { 2 - 3 } & Peaty Clay + Woven Geo textile Soaked & 0.0505 \\
\cline { 2 - 3 } & Peaty Clay + Woven Geo textile Un Soaked & 0.2574 \\
\cline { 2 - 3 } & Peaty Clay + Non-Woven Geo textile Soaked & 0.0028 \\
\cline { 2 - 3 } & Peaty Clay + Non-Woven Geo textile Un soaked & 0.0329 \\
\hline
\end{tabular}

\section{CONCLUSION}

\section{Overview}

The difference in reliability values of the improved soil for the locations studied is negligible, with a nominal value of 3 $\%$ alteration between the highest ant the lowest for most of the results. However, the maximum value of reliability for the CBR and UCS occurred at $6 \%$ addition of chemical for most of the chemicals used, while that of cement occurred at $10 \%$.

\section{Unconfined Compressive Strength Test (UCS)}

$>$ alcium Oxide: It was observed that the UCS result of the stabilized peat increased by the addition of Calcium oxide up to $6 \%$ of the wet soil and after that it decreased significantly i.e. optimal reliability. Increase in calcium oxide content beyond a certain limit was found to have a reduced shear strength gain.

$>$ Calcium Hydroxide displayed the same reliability trend as Calcium oxide, but with lower values which were close for all curing days. Calcium Hydroxide had the third best reliability values after calcium oxide and cement.

$>$ Calcium Chloride showed peak reliability at $6 \%$ for all curing days. Thus Calcium chloride had a positive effect on the shear strength of soil.

$>$ Reliability increased with the percentage of cement added. It optimized at $10 \%$ i.e. optimal reliability.

$>$ Aluminum Hydroxide was the only chemical to reach an optimal level of reliability at just $4 \%$ addition of chemical i.e. it didn't alter the soils $\mathrm{pH}$.

$>$ Sodium Silicate reached an optimal level of reliability at $8 \%$ for all periods of curing.

\section{California Bearing Ratio Test (CBR)}

$>$ Calcium Oxide displayed maximum values of reliability of all chemicals used with a peak at $6 \%$ addition.

$>$ Cement - peak reliability occurred at $10 \%$ addition in 28 days curing period. Just like the UCS test, cement was the only material that exhibited behavioral increase till the summit.

$>$ Aluminum Hydroxide - peak reliability occurred at $4 \%$

\section{Geo textile}

Woven Soaked and Un soaked: Absorbed stress by the warp and weft without much mechanical expansion. This gave them a relatively high modulus or stiffness and thus was reliable as a soil improvement technique.
The structural ability of soil was improved by the tensile strength of the geo textile. They function as reinforcing steel by providing strength that help to hold the soil in place.

\section{Conclusion}

By virtue of the outcome of this study the following conclusions were drawn:

1. Peaty clay soil improved with Cement, Calcium compounds and geo textile materials in the location of study. UCS and CBR tests showed some improvement in strength which was directly proportional to the reliability values obtained.

2. Reliability of improved soil, using the two tests, increased with increase in percentage of chemicals added from $2-10 \%$ by weight of the soil sample but to a certain level ( $6 \%$ in most cases) before the reliability value starts dropping.

3. Of all the chemicals used in the research, Calcium Oxide gave the highest value of reliability for both tests carried out, with an average value of 0.9905 for UCS test and 0.9981 for CBR test as against 0.9784 and 0.9967 in cement.

4. Reliability increased with duration of curing of the improved soil samples before tests were run.

5. Cement behaved differently in comparison with other chemicals used, as its reliability value for both tests increased with increase in percent of cement added. Sodium Silicate reliability peaked at $8 \%$, as against $6 \%$ for other chemicals.

6. Geo textile materials were not really suitable to improve the strength of the peaty clay soil due to its poor values of reliability in CBR test.

7. When cost of execution is compared with the reliability values, for optimization purpose, cement is the best option followed by Calcium oxide while Sodium Silicate is the last.

\section{REFERENCES}

[1] Phoon, K. K., (2004). Towards A Reliability -Based Design for Geotechnical Engineering. Special lecture for Korean Geotechnical Society, Seoul. 9th July, 2004.

[2] Mitchell, J. K. (1993): Fundamentals of Soil Behavior. 2nd Ed. John Wiley \& Sons Inc., New

[3] Olorunfemi, B. N. (1984). Factors influencing the Geochemistry of Lateritic Soils, Green schistAmphibolite Meta- Tectonic Belt, SW Nigeria. Chem. 

Geol. 42, 261-275, Elsevier Sc
Pub. B. V.
Company, New Delhi, 1999.

Amsterdam.

[11] Tiwari, S. K. \& Kumawat, N. K. (2014). Recent Developments in Ground Improvement Techniques-A Review, International Journal of Recent Development in engineering and Technology, 2(3).

[5] Hamidi, B., Nikraz, H., \& Varaksin, S., (2009). A Review on Impact Oriented Ground Improvement Techniques. J. Australian Geo mechanics, 2, 17-24.

[6] Mitchell, J. K. (1981). Soil Mechanics and Foundation Engineering. Proc. 10th ICSMFE, (1), Stockholm, Sweden, 1981.

[7] Chris K., (2014). Land and Water, a brief History of Geo textiles, A 40 year Update. On -line publication. Retrieved from www.geosynthetica.netlresources/briefhistorygeotextiles. $26^{\text {th }}$ February, 2019.

[8] NYSDOT (2013): Ground Improvement Technology. Geotechnical Design Manual of New York State Department of Transportation. 14-69.

[9] Elias, V., Welsh, J., Wanen, J., Lukas, R., Collin, J. G., \& Berg, R. R., (2006). Ground Improvement Methods, Vol. 1, Federal Highway Administration Publication No. NHI- 06-020, Washington, D.C.

[12] Geotechnical Engineering Manual (2013). Geotechnical Engineering Sector, Minnesota Department of Transportation. Geotechnical Engineering Section Office of Materials and Road Research 1400, Gervais Ave Maplewood, MN55109.

[13] Gregory, R. B. \& John, T. C. (2003): Reliability and Statistics in Geotechnical Engineering. John Wiley and Sons Ltd. West Sussex, England. 303-469

[14] Enrico Z., (2007). An Introduction to the Basics of Reliability and Risk Analysis. World Scientific Publishing Co. Pte. Ltd. Singapore. 77 -81.

[15] Khattab, S. A. A., Al-Mukhtar M., and Fleureau, J. M. (2007). Long-Term stability Characteristics of a LimeTreated Plastic Soil, J. Mater. Civ Eng. 19(4), 358-366.

[16] B. S 1377 (1990). Methods of tests for engineering purposes. Parts: 1, 2, 4, 7 and 8. British Standard Institution.

[10] Purushothama Raj, P. (1999). Ground Improvement Techniques, Tata McGraw-Hill Publishing

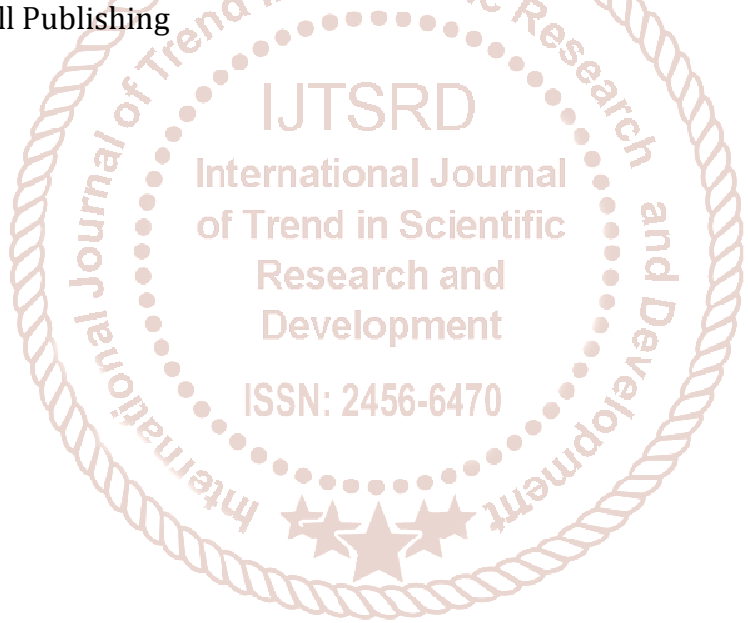

